\title{
Temperature Rise Within the Pulp Chamber During Composite Resin Polymerisation Using Three Different Light Sources
}

\author{
A. Santini*, C. Watterson and V. Miletic
}

Edinburgh Postgraduate Dental Institute, The University of Edinburgh, Lauriston Place, Edinburgh, EH3 9HA. UK

\begin{abstract}
The purpose of the study was to compare temperature rise during polymerisation of resin based composites (RBCs) with two LED light curing units (LCUs) compared to a halogen control light.

Methods: Forty-five extracted molars, patients aging 11-18 years were used. Thermocouples (TCs) were placed in contact with the roof of the pulp chamber using a 'split-tooth' method. Teeth were placed in a water bath with the temperature of the pulp chamber regulated at $37^{\circ} \pm 1^{\circ} \mathrm{C}$.

Group 1 (control): Prismatics ${ }^{\circledR}$ Lite II (Dentsply Detrey, Konstanz, Germany), a halogen LCU, light intensity 500 $\mathrm{mW} / \mathrm{cm}^{2}$.

Group 2: Bluephase ${ }^{\circledR}$ ( Ivoclar Vivadent, Schaan, Liechtenstein), light intensity $1100 \mathrm{~mW} / \mathrm{cm}^{2}$. Group 3:Elipar Freelight2 (3M ESPE, Seefeld, Germany), light intensity $1000 \mathrm{~mW} / \mathrm{cm}^{2}$. Temperature changes were continuously recorded with a data logger connected to a PC.

Results: Significantly higher temperature rise was recorded during bond curing than RBC curing in all 3 groups. (Halogen; $p=0.0003$ : Bluephase; $p=0.0043$ : Elipar; $p=0.0002$.). Higher temperatures were recorded during polymerisation of both Bond and RBC with both LED sources than with the halogen control. There was no significant difference between the two LED,LCUs (Bond:p=0.0279: RBC p=0.0562: Mann-Whitney).

Conclusion: The potential risk of pulpal injury during RBC polymerisation is increased when using light-curing units with high energy output compared to low energy output light sources. The rise is greatest when curing bonding agent alone and clinicians are advised to be aware of the potential hazard of thermal trauma to the pulp when using high intensity light sources. However the mean temperature rise with all three units was below the limits normally associated with permanent pulp damage.
\end{abstract}

Key Words: Light curing units, resin based composites, pulp temperature rise.

\section{INTRODUCTION}

Tooth coloured resin based composites (RBCs) have been traditionally cured with a halogen light source with a light intensity of approximately $400 \mathrm{~mW} / \mathrm{cm}^{2}$. More recently, in attempts to reduce clinical times for operator and patients and to achieve a deeper, more effective cure, higher intensity light sources have been introduced. These newer lights have tended to move away from the traditional halogen type to the higher intensity LED source which can have a light intensity of up to $1200 \mathrm{~mW} / \mathrm{cm}^{2}$. Research has shown that the process of light curing composite materials causes the temperature within the pulp chamber to increase $[1,2]$ and that pulp vitality is compromised if there is a temperature rise of between $5-6{ }^{\circ} \mathrm{C}$ in the pulp [3], however, this has been questioned in more recent studies [4].

Previous studies have shown that light polymerisation of RBCs with conventional light curing sources cause an intrapulpal temperature rise of only a few degrees [5, 6]. More recent high intensity lights represent a potential hazard for

*Address correspondence to this author at the Edinburgh Postgraduate Dental Institute, The University of Edinburgh, Lauriston Place, Edinburgh, EH3 9HA. UK; Tel: 0131536 4970; Fax: 0131536 4971;

E-mail: ariosantini@hotmail.com the tooth and may cause a rise in excess of this critical value and are therefore a potential source of necrosis of pulp tissue [7-9].

Several factors may affect temperature change, including the intensity of the light source, the exposure time [10-12] and the state of the remaining dentine beneath the cavity [1315]. The state of pulp tissue will also be a factor as will its reparative ability [16] In addition, those related to RBC are, amongst others, shade [17] and filler content [18, 19].

The aim of this study was to evaluate temperature rise within the pulp chamber during RBC polymerisation with two high intensity light emitting diode light curing units (LED), Bluephase ${ }^{\circledR}$ (Ivoclar Vivadent, Schaan, Liechtenstein.) and Elipar Freelight2 (3M ESPE, Seefeld, Germany). A conventional halogen light was used as a control, (Prismatics ${ }^{\circledR}$ Lite II , Dentsply De Trey, Konstanz, Germany).

The null hypothesis was that there was no difference between pulp chamber temperature rises with two different high intensity LED lights and a conventional halogen LCU.

\section{METHODS AND MATERIALS}

Forty five non-carious permanent molars that had been extracted for orthodontic purposes and stored in $0.2 \%$ thy- 
mol for not more than 4 months, were selected. Informed consent was obtained from patients for the use of these teeth for research purposes. Patient age range was 11-18 years. Ethical approval was granted by the Ethics Committee, Lothian NHS Board, Edinburgh, Scotland, to use such teeth in this study.

Prior to the study the teeth were cleaned using an ultrasonic scaler of all superficial debris. For the duration of the experiment the teeth were kept in distilled water at $37^{\circ} \pm 2^{\circ} \mathrm{C}$ to ensure adequate hydration of the dental tissues.

To standardise cavity preparation with respect to cavity depth, cavity volume and remaining dentine thickness (RDT), as well as standardising the distance of the light source from the RBC during curing, the following procedures were undertaken (Fig. 1).

A. The apices of the roots were cut off and the tooth embedded in clear acrylic up to the amelo-cemental junction.

B. A diamond bur, no BD456 (UnoDent,Israel) in a high speed hand-piece with water spray was used to reduce cusps to create a flat occlusal plane just into dentine.

C. Using the same diamond bur, a preliminary cavity was cut into dentin, but not extending more than $1.5 \mathrm{~mm}$ from the occlusal plane. A class I large Cerana diamond bur, height $3 \mathrm{~mm}$; top diameter $4 \mathrm{~mm}$; bottom diameter $3 \mathrm{~mm}$ (Nordiska Dental, Angelholm, Sweden), normally (sug-
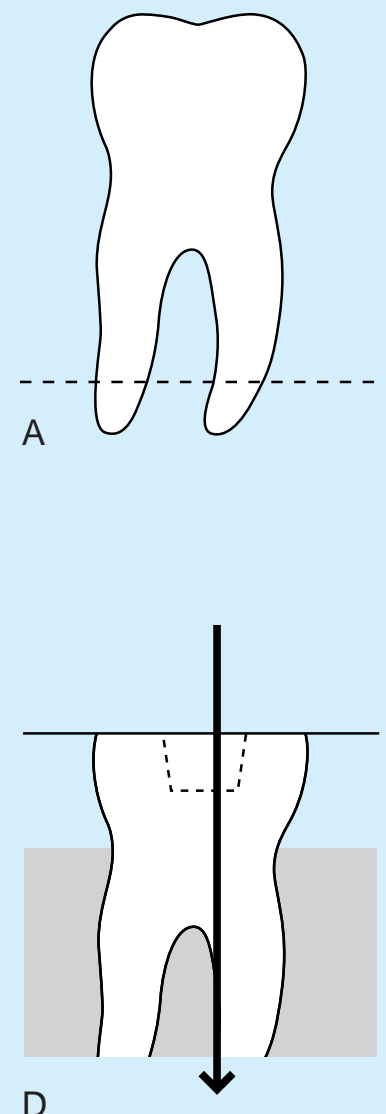

D

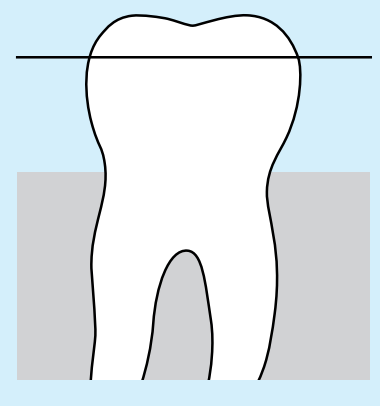

B

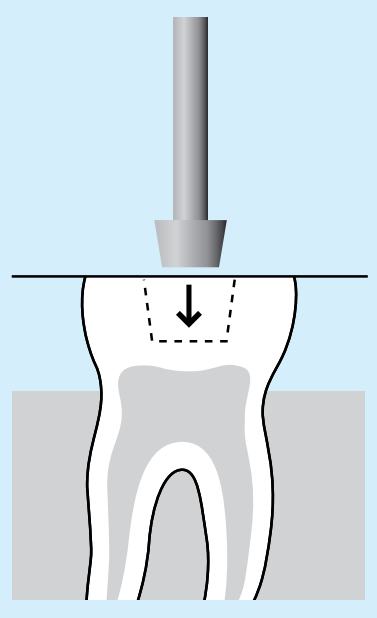

E

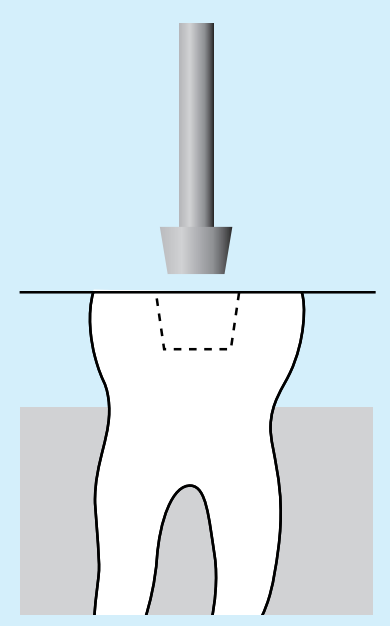

C

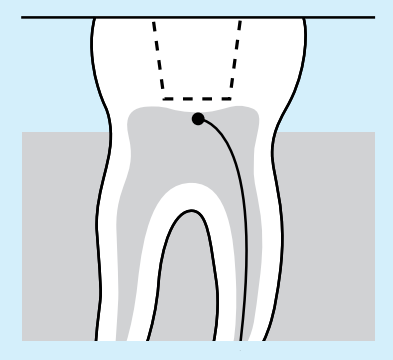

$\mathrm{F}$

Fig. (1). A. The root apices were cut off and the tooth embedded in clear acrylic up to the amelo-cemental junction. B. A diamond bur was used to reduce cusps to create a flat occlusal plane just into dentine. C. Using the same diamond bur, a preliminary cavity was cut into dentine, but not extending more than $1.5 \mathrm{~mm}$ from the occlusal plane. A large Cerana diamond bur (Class 1 type), height $3 \mathrm{~mm}$;top diameter $4 \mathrm{~mm}$;bottom diameter $3 \mathrm{~mm}$ was used to enlarge the initial cavity. At this stage the depth of the cavity was under prepared. D. The teeth were then sectioned through the prepared cavity, $1 \mathrm{~mm}$ off-centre, along the mesio-distal plane. All remaining remnants of pulp tissue were removed by washing the cavity for five minutes with $5 \%$ sodium hypochlorite and flushing out with distilled water. E. A standard cavity with a RDT of approximately $0.5 \mathrm{~mm}$ was created using the Cerana bur. The depth of the cavity was then standardised to be $2 \mathrm{~mm}$ deep by further reduction of the flat occlusal pale. F. Both sections of each tooth were photographed using an image analysis system and the average RDT was calculated from 5 randomly selected sites per section. Using a tungsten carbide bur, a groove in one root was prepared to receive the leads of the TC which were glued to the dentin of the roof exactly in the midline of the cavity, in the larger of the two sections. The pulp chamber was injected with ECG gel. 
gest take out normally, without any other comment) used to prepare standardized cavities for ceramic inserts was used to enlarge the initial cavity. At this stage the depth of the cavity was under prepared.

D. The teeth were then sectioned through the prepared cavity, $1 \mathrm{~mm}$ off-centre, along the mesio-distal plane using a slow speed saw (Isomet ${ }^{\circledR}$, Buehler, Lake Bluff, Illinois, USA). All remaining remnants of pulp tissue were removed by washing the cavity with $5 \%$ sodium hypochlorite and flushing out with distilled water.

E. Cerana bur was then used to create a standard cavity with a RDT of approximately $0.5 \mathrm{~mm}$. The depth of the cavity was equal to the size of the bur head and reduction of the flat occlusal plane was sometimes necessary to achieve this.

F. Using an image analysis system (Olympus Camedia and SZ-CTV Olympus, Tokyo, Japan) both sections of each tooth were photographed and the average RDT was calculated from 5 randomly selected sites per section. Using a tungsten carbide bur one root was prepared to receive the leads of the thermocouples (TC) (USB-Temp, Measurement Computing, Norton, MA, USA) and the TC head fixed in position with Loctite ${ }^{\circledR}$ Super glue, (Henkels Consumer Adhesives, Winsford, Cheshire, UK) to the dentine of the pulp chamber roof exactly in the midline of the cavity, in the larger of the two sections. The pulp chamber was injected with ECG gel. The two sections were then carefully glued together using Araldite ${ }^{\circledR}$ adhesive (Bostik Findlay, Staffordshire, UK).

Specimens were then randomly assigned to one of 3 groups according to the type of light source to be used for polymerisation of the RBC. The intensity of the halogen LCU was monitored by a Demetron Radiometer (Demetron Kerr, Danbury, CT, USA) while the intensity of the two Led, LCUs was monitored via their integrated radiometer.

Group 1: Halogen Control Light- Prismatics ${ }^{\circledR}$ Lite II: Light intensity $500 \mathrm{~mW} / \mathrm{cm}^{2}$. Adper Prompt L-Pop (3M ESPE, St. Paul, MN, USA. Lot 284081) dentine bonding agent was applied to the prepared teeth. Bonding agent was cured for 10 seconds and a RBC (A2 (Image:shade A2:Septodont, Cedex, France. Lot D4600-3) was immediately placed and cured for 20 seconds.

Group 2: Bluephase ${ }^{\circledR}$ : Light intensity $1100 \mathrm{~mW} / \mathrm{cm}^{2}$. Adper Prompt L-Pop bonding agent was applied to the prepared teeth. Bonding agent was cured for 10 seconds and a RBC (Image: Shade A2) was immediately placed and cured for 20 seconds.

Group 3: Elipar Freelight2 LED (3M ESPE, Seefeld, Germany): Light intensity $1000 \mathrm{~mW} / \mathrm{cm}^{2}$. Adper Prompt L-Pop adhesive was applied to the prepared teeth. Bonding agent was cured for $10 \mathrm{sec}-$ onds before a RBC restoration (Image:shade A2), was immediately and cured for 20 seconds.

During curing of the bonding agent and $\mathrm{RBC}$, the cavity was covered with a glass microscope slide to ensure the light source was kept at a standard distance from the base of the cavity and the LCU tip help in contact with the slide.

Temperature change was recorded by TCs connected via a data logger to a computer and temperature was recorded using software package TracerDAQ ${ }^{\mathrm{TM}}$ (Measurement Computing, Norton, MA, USA) continuously from the time of application of the bonding agent, through curing of the bonding agent, placement and curing of the RBC. The results were statistically analysed using GraphPad InStat software (GraphPad, San Diego, USA.).

\section{RESULTS}

There was no significant difference in RDT in any of the three groups. $\mathrm{P}=0.9549$ (Kruskal-Wallis; nonparametric ANOVA).

There was a significant difference in pulp chamber temperature rise during bond curing with both LED LCUs compared to the halogen control $(\mathrm{p}<0.05$, Kruskal-Wallis; nonparametric ANOVA) (Table 1).

However, there was no significant difference between the two LED LCUs (Bond: $\mathrm{p}=0.0279$ : RBC $\mathrm{p}=0.0562$ : MannWhitney).

There was a significant difference in pulp chamber temperature rise during RBC curing with Bluephase ${ }^{\circledR}$ compared to the halogen control $(\mathrm{p}<0.001$, Kruskal-Wallis; nonparametric ANOVA ) whereas temperature rise during RBC curing with Elipar Freelight 2 was higher compared to the halogen LCU, but not statistically significant ( $p>0.05$, Kruskal-Wallis; nonparametric ANOVA ) (Table 2).

With both LED LCUs and the halogen control, the results showed a greater temperature rise during the curing of the bonding agent alone compared to that recorded when the RBC was cured (Table 3 ).

Table 1. Temperature Rise in the Pulp Chamber During Bond Curing

\begin{tabular}{|c|c|c|c|}
\hline & Halogen & Bluephase $^{\circledR}$ & Elipar Freelight 2 \\
\hline \hline Median $\left({ }^{\circ} \mathrm{C}\right)$ & 3.8 & 5.2 & 4.4 \\
\hline Minimum $\left({ }^{\circ} \mathrm{C}\right)$ & 2.8 & 3.0 & 3.9 \\
\hline Maximum $\left({ }^{\circ} \mathrm{C}\right)$ & 4.9 & 7.1 & 6.4 \\
\hline Lower 95\% conf. limit & 3.482 & 4.824 & 4.303 \\
\hline Upper 95\% conf. limit & 4.144 & 6.056 & 5.123 \\
\hline
\end{tabular}


Table 2. Temperature Rise in the Pulp Chamber During RBC Curing

\begin{tabular}{|c|c|c|c|}
\hline & Halogen & Bluephase $^{\circledR}$ & Elipar Freelight 2 \\
\hline \hline Median $\left({ }^{\circ} \mathrm{C}\right)$ & 2.8 & 4.2 & 3.5 \\
\hline Minimum $\left({ }^{\circ} \mathrm{C}\right)$ & 1.3 & 1.7 & 2.0 \\
\hline Maximum $\left({ }^{\circ} \mathrm{C}\right)$ & 3.9 & 5.6 & 5.2 \\
\hline Lower 95\% conf. limit & 2.102 & 3.582 & 3.051 \\
\hline Upper 95\% conf. limit & 3.058 & 4.805 & 3.976 \\
\hline
\end{tabular}

Table 3. Statistical Analysis of Temperature Rise During Bond Curing vs. RBC Curing

\begin{tabular}{|c|c|c|}
\hline & p Value & Significance \\
\hline \hline Halogen:Bond vs. Halogen:RBC & 0.0003 & $\mathrm{~S}$ \\
\hline Bluephase:Bond vs. Bluephase:RBC & 0.0043 & $\mathrm{~S}$ \\
\hline Elipar:Bond vs. Elipar:RBC & 0.0002 & $\mathrm{~S}$ \\
\hline
\end{tabular}

(Mann-Whitney test, nonparametric ANOVA).

\section{DISCUSSION}

Most manufacturers have in the recent past, introduced to the market, light curing units with irradiance approaching $1000 \mathrm{~mW} / \mathrm{cm}^{2}$ in an attempt to reduce clinical working time and increase the depth of cure. Early reports suggest that LED curing units are less harmful to the pulp, but this conclusion should be interpreted with a degree of caution as these early units usually operated in the range of $400 \mathrm{~mW} / \mathrm{cm}^{2}$. The LED units tested in the current study were $1000 \mathrm{~mW} / \mathrm{cm}^{2}$. Though the mean temperature rise was lower than $5.5^{\circ} \mathrm{C}$, the temperature frequently cited as sufficient to cause pulp cell damage, the maximum recorded temperature for the Bluephase light was $5.6^{\circ} \mathrm{C}$.

The present results showed that high intensity LED lights operating at approximately $1100 \mathrm{~mW} / \mathrm{cm}^{2}$ caused a significantly higher temperature rise within the pulp chamber compared with the conventional halogen lights which operate at about $500 \mathrm{~mW} / \mathrm{cm}^{2}$. The amount of heat generated was influenced by characteristics of the light curing unit and this is in agreement with previous studies [1,2]. There was a significantly higher temperature rise with both LEDs compared to the conventional halogen control LCU which is in agreement with former studies of Shorthall and Harrington [1] who concluded that it was the type of LCU, though Hanning found that light intensity rather than the type of light source was important [20] In the present study the Bluephase ${ }^{\circledR}$ LCU with a light intensity of $1100 \mathrm{~mW} / \mathrm{cm}^{2}$ produced higher temperature rises than the Elipar LCU, with light intensity of $1000 \mathrm{~mW} / \mathrm{cm}^{2}$, though this was not at a significant level. A critical factor in reducing thermal transfer to the pulp tissue is the low thermal conductivity of dentine. In spite of the low thermal conductivity of dentine the potential for pulp damage is greater as the number of dentinal tubules increases per unit area in deep cavity preparation; there is an increase in pulpal trauma from heat as the RDT decreases.
Clinicians should be cautioned by the results of the present study to refrain from excessively long bonding times when using some LED units at $1100 \mathrm{~mW} / \mathrm{cm}^{2}$. If the LED unit has a low irradiance mode this should be used for curing the bonding adhesive and the higher mode restricted to curing RBCs. Consideration should be given to the placement of a lining in very deep cavities.

The particularly vulnerable pulp cells are the post-mitotic odontoblast layer of cells just beneath the predentin, forming the roof of the pulp chamber. There is considerable debate as to whether these cells can be replaced by differentiation of undifferentiated mesenchymal cells originating in the deeper pulp tissue [3, 21-23]. It is important therefore to record the temperature in this specific region.

Previous studies have recorded temperature by inserting a thermocouple into the pulp chamber through a preformed channel in the root and therefore the precise position of the electrode is unknown at the time of placement $[1,20]$. A further problem in previous experiments are that the RDT above the thermocouple is unknown at the time of recording temperature change, [20] and was not standardised. As dentine constitutes a significant insulator to heat transfer, the result of such studies can be questioned.

Other studies have constructed pulp chamber models to simulate the in vivo situation [24]. The present study used a "split tooth" technique [25], whereby each tooth was sectioned to allow cavity and TC placement standardisation. Many variables which would otherwise exist were eliminated. As each cavity was of a standard depth and shape then the bulk of composite placed each time was similar. The shade of composite may also influence the temperature rise [17-19] so to eliminate this variable for the duration of the experiment only shade A2 was used.

The 'split tooth' technique allowed each thermocouple's accurate placement, just touching the roof of the pulp cham- 
ber at the region occupied by the odontoblast layer. The heads of TCs were held securely in place by a drop of Loctite $^{\circledR}$.

Each tooth was photographed to allow the remaining dentine thickness to be calculated using the image analysis system. Sectioned halves were accurately repositioned and sealed together to leave no gaps with Araldite, and ECG Gel was placed in the pulp chamber to replicate pulp tissue. Each tooth was placed in a water bath at $37^{\circ} \pm 2{ }^{\circ} \mathrm{C}$ and held at this temperature for the duration of the study. Although the water bath was set to the physiological temperature of $37^{\circ} \mathrm{C}$, the exact mechanisms by which heat is dissipated in vivo could not be recreated. Blood flow through pulp tissue is a mechanism for heat dissipation and heat may also be absorbed by the gingival connective tissues [13]. Therefore, temperature values measured in this study cannot be directly applied to temperature changes in vivo. The experiment set up did not account for blood circulation which occurs in the natural, vital pulp chamber or for fluid movement in the dentinal tubules. The experimental values obtained may therefore be higher than those occurring in vivo.

\section{CONCLUSIONS}

There was a significantly greater temperature rise within the pulp with high intensity light sources over a traditional halogen lamp as a control. The potential risk of pulpal injury during composite resin polymerization is increased when using light-curing units with high energy output as compared to low energy output light sources. However the mean temperature rise with both LED and halogen is below the limits normally accepted as causing pulp damage. The rise is greatest when curing bonding agent alone and clinicians are advised to be aware of the potential hazard of thermal trauma to the pulp when using the new generation high intensity light sources. Thought should be given to protecting the pulp with an insulating lining, particularly in deep cavities.

\section{REFERENCES}

[1] Shortall AC, Harrington E. Temperature rise during polymerization of light-activated resin composites. J Oral Rehabil 1998; 25: 90813.

[2] Uhl ARW, Mills RW, Jandt KD. Polymerization and light-induced heat of dental composites cured with LED and halogen technology. Biomaterials 2003; 24: 1809-20.

[3] Zach L, Cohen G. Pulp response to externally applied heat. Oral surg Oral med Oral pathol 1965; 19: 515-30.

[4] Baldissara P, Catapano S, Scotti R. Clinical and histological evaluation of thermal injury thresholds in human teeth: a preliminary study. J Oral Rehabil 1997; 24: 791-801.

[5] Thompson HF, Gomez HF, Puckett AD. Pulpal temperature changes after exposure to a light curing source. J Dent Res 1997; 76: 79. (abstract).
[6] Bennett GE, Blank FJ, Robertello FJ, Pelleu GB. Thermal effects of visible-light and chemically cured resins. J Dent Res 1984; 63: 199. (abstract)

[7] Peutzfeld A, Sahafi A, Asmussen E. Characterization of resin composites polymerized with plasma arc curing units. Dent Mater 2000; 16: 330-6.

[8] Loney RW, Price RB. Temperature transmission of high-output light-curing units through dentin. Oper Dent 2001; 26: 516-20.

[9] Fano L, Ma WY, Marcoli PA, Pizzi S, Fano V. Polymerization of dental composite resins using plasma light. Biomaterials 2002; 23 : 1001-15.

[10] Lloyd CH, Joshi A, McGlynn E. Temperature rises produced by light sources and composites during curing. Dent Mater 1986; 2 : 170-4.

[11] Goodis HE. The effect of glass ionomer liners in lowering pulp temperatures during composite placement, in vivo, in vitro. Dent Mater 1993; 9: 146-50.

[12] Goodis HE, White JM, Andrews J, Watanabe LG. Measurement of temperature generated by visible-light-cure lamps in an in vivo, in vitro model. Dent Mater 1989; 5: 230-4.

[13] Aguiar FH, Barros GK, dos Santos AJ, Ambrosiano GM, Lovadino JR. Effect of polymerization modes and resin composite on the temperature rise of human dentin of different thicknesses: an in vivo, in vitro study. Oper Dent 2005; 30: 602-7.

[14] Hansen EK, Asmussen E. Correlation between depth of cure and temperature rise of a light-activated resin. Scand J Dent Res 1993; 101: 176-9.

[15] Ozturk B, Ozturk AN, Usumez A, Usumez S, Ozer F. Temperature rise during adhesive and resin composite polymerization with various light curing sources. Oper Dent 2004; 29: 325-32.

[16] Raab WH. Temperature related changes in pulpal microcirculation. Proc Finn Dent Soc 1992; 88(Suppl 1): 469-79.

[17] Uhl A, Volpel A, Sigusch B. Polymerization and light-induced heat of dental composites cured with LED and halogen technology. Biomaterials 2003; 24: 1809-20.

[18] Al-Quadah AA, Mitchell CA, Biagioni PA, Hussey DL. Effect of composite shade, increment thickness and curing light on temperature rise during photocuring. J Dent 2007; 35: 238-45.

[19] Christensen RP, Palmer TM, Ploeger BJ, Yost MP. Resin polymerization problems--are they caused by resin curing lights, resin formulations, or both? Compend Contin Educ Dent Suppl 1999; (25): S42-54

[20] Hannig M, Bott B. In vivo, in-vitro pulp chamber temperature rise during composite resin polymerization with various light-curing sources. Dent Mater 1999; 15: 275-81.

[21] Ruch JV, Lesot H, Bègue-Kirn C. Odontoblast differentiation. Int J Dev Biol 1995; 39: 51-68.

[22] Ruch JV. Odontoblast commitment and differentiation. Biochem Cell Biol 1998; 76: 923-38.

[23] Narayanan K, Srinivas R, Ramachandran A, Hao J, Quinn B, George A. Differentiation of embryonic mesenchymal cells to odontoblast-like cells by over expression of dentin matrix protein. Proc Natl Acad Sci USA 2001; 98: 4516-21.

[24] Uhl A, Volpel A, Sigusch BW. Influence of heat from light curing units and dental composite polymerization on cells in vitro. J Dent 2006; 34: 298-306.

[25] Millen C, Ormond M, Richardson G, Santini A, Miletic V, Kew P. A study of temperature rise in the pulp chamber during composite polymerization with different light curing units. J Cont Dent Pract 2007; 8: 1-13. 